OPEN ACCESS

Edited by:

Rodolfo A. Rey,

Centro de Investigaciones Endocrinológicas "Dr. César Bergadá"

(CEDIE) - FEl - División de

Endocrinología, Hospital de Niños

Ricardo Gutiérrez (CONICET),

Argentina

Reviewed by:

Sasha R. Howard,

Queen Mary University of London,

United Kingdom

Yehuda Limony,

Soroka Medical Center, Israel

${ }^{*}$ Correspondence:

Takeo Fujiwara

fujiwara.hlth@tmd.ac.jp

Specialty section: This article was submitted to

Pediatric Endocrinology,

a section of the journal

Frontiers in Endocrinology

Received: 30 August 2021 Accepted: 29 November 2021 Published: 21 December 2021

Citation:

Katagiri A, Nawa N and Fujiwara T (2021) Association Between Paternal Separation During Early Childhood and Pubertal Timing Among Girls Using Longitudinal Birth Cohort in Japan.

Front. Endocrinol. 12:766728.

doi: 10.3389/fendo.2021.766728

\section{Association Between Paternal Separation During Early Childhood and Pubertal Timing Among Girls Using Longitudinal Birth Cohort in Japan}

\author{
Aomi Katagiri ${ }^{1}$, Nobutoshi Nawa ${ }^{2}$ and Takeo Fujiwara ${ }^{1 *}$ \\ 1 Department of Global Health Promotion, Tokyo Medical and Dental University, Tokyo, Japan, ${ }^{2}$ Department of Medical \\ Education Research and Development, Tokyo Medical and Dental University, Tokyo, Japan
}

Introduction: Previous studies have shown that paternal absence leads to earlier pubertal timing among girls in high-income countries. Despite the low divorce rate in Japan, paternal separation is commonly seen due to a unique corporation system, tanshin funin, where employees relocate with their spouses and children. We examined paternal separation, including paternal absence (due to divorce or paternal death) and paternal tanshin funin, during early childhood as a predictor of earlier girl's pubertal development, assessed as age at peak height velocity (PHV).

Methods: This study examined 15214 girls from a longitudinal survey conducted in Japan from 2001 to 2016 by the Ministry of Health, Labor and Welfare. Paternal separation was determined by the occurrence through annual surveys conducted at ages 0.5 to 4.5 years. Outcome was defined as age at PHV between ages 6 to 15 years. We conducted linear regression, adjusted for potential confounders and other covariates.

Results: Continuous father cohabitation was seen in $88.7 \%$ of households, while paternal separation was experienced 1-2, 3-4 and 5 times (always) among 7.4\%, 2.8\% and 1.1\% of households, respectively. Girls who confronted continuous paternal separation (5 times) experienced 0.42 years earlier [95\% confidence interval $(\mathrm{Cl}):-0.75,-0.10]$ age at PHV compared to their peers who always lived with their fathers.

Conclusion: Girls who experienced paternal separation throughout ages 0.5 to 4.5 years experienced PHV earlier.

Keywords: Paternal separation, paternal absence, puberty, age at peak height velocity, Japan, social epidemiology

\section{INTRODUCTION}

Earlier pubertal timing in girls has been linked to higher risk of breast cancer $(1,2)$ and ovarian cancer $(2,3)$ due to the earlier start of undifferentiated breast cell growth and increased number of ovulations. In addition, early pubertal timing in girls also has an increased risk for psychological dysfunction (e.g., depression and anxiety) (2). These associations took potential confounders into 
account such as parental socioeconomic status (SES), and early childhood disadvantage. Early pubertal timing is determined by biological factors (4), social factors [such as low family income, low parental education level, absence of biological father (5), stepfather presence $(2,5)$, family conflict $(2)$, maltreatment (6), urban residency (5)], perinatal factors [such as small for gestational age (7) and maternal overweight during pregnancy (8)], and high BMI before puberty (2).

While parental divorce and father death is an obvious stressor, we hypothesize that physical paternal absence regardless of marital status may also create stress in the household. In Japan, the divorce rate remain low compared to other advanced countries (9). However, there are many more girls who face paternal separation due to tanshin funin. Tanshin funin is a unique Japanese corporate system in which an employee is transferred to a distant office without his or her family. Nearly $54 \%$ of employees in Japan who have a family chose tanshin funin (10), whereas in Western countries families tend to relocate together (11). The households that experience tanshin funin are not economically disadvantaged, as they received remittances from the father, and thus differ from the single female households that have been studied in previous studies. However, the physical absence of a father might still affect pubertal timing due to both the physical paternal absence and functional absence having an impact on the mother's stress level, which in turn results in increased anxiety over the children (11).

Several studies have examined the association between paternal absence and pubertal timing among girls (4, 12, 13). Of note, paternal absence that occurs between the first five years of life (from birth to the age offive) shows stronger association with earlier maturation compared to that occurring in the subsequent five years of life (ages 6-10 years old) (4). The importance of exposure during infancy and early childhood is also consistent with evolutionary theory (14). Although some recent studies found that paternal absence is not associated with early pubertal timing in low to middle income countries, there is consensus that such association remains in high-income countries (15). The variations of paternal separation until the age of five span across a range, in terms of cumulative duration, instability and onset. However, to our knowledge no studies have examined how variations in these patterns might affect pubertal timing in girls. The Japanese society presents an interesting setting to test the hypothesis that paternal separation is correlated with accelerated maturation.

Accordingly, the objectives of this study are to assess the effects of 1) cumulative paternal separation 2) instability of paternal separation and 3) onset of continual paternal separation on girl's pubertal timing in Japan. Instability of paternal separation can be regarded as stress because such girls may feel more stressed compared to the reference group of girls whose fathers are always present.

\section{METHODS}

\section{Sample}

This study used de-identified data from the Longitudinal Survey of Newborns in the 21st Century, collected by the Ministry of Health, Labor and Welfare in Japan from 2001 to 2016 (16). All babies born between January 10th to 17 th and July 10th to 17th in 2001 were identified from the national register $(n=53575)$. Questionnaires were sent via postal mail when children were 0.5, $1.5,2.5,3.5,4.5,5.5,7,8,9,10,11,12,13,14,15$ years old, and all data were parent- or self-reported. Participants who did not reply for two years in a row were regarded as dropout. At age 0.5 years, 47015 children participated.

We excluded all male participants $(n=24$ 425). After this exclusion, we then excluded participants with missing exposure variables $(n=4483)$ and participants whose height $z$-score was less than -5 standard deviation (SD) or larger than 3 SD based on World Health Organization (WHO) standards ( $\mathrm{n}=2$ 893) (17). This resulted in an analytic sample size of 15214 girls (Figure 1).

A previous profile paper of this cohort showed that this cohort is a representative sample of Japanese children because no difference in the distributions of socio-demographic characteristics such as sex, birthweight, single/multiple births, birth order, birth in/out of wedlock and main employment of the household was observed between responders and the target population (16).

This study was conducted according to the latest guidelines provided in the Declaration of Helsinki and Ministry of Health, Labor and Welfare of Japan and was approved by the ethics committee of Tokyo Medical and Dental University (M2019066). This study involved a secondary data analysis of deidentified data from the survey by the Ministry of Health, Labor and Welfare in Japan in which consent to participate was assumed upon return of the questionnaires to the Ministry of Health, Labor and Welfare.

\section{Measurements}

Paternal separation included both 'no father residency' and 'on tanshin funin'. Father residency was determined from questionnaire responses across survey waves one to five, namely ages 0.5 to 4.5 years. The questionnaire asked responders to mark all members who live with the child and required to include the father if he came back once in three months during tanshin funin. Paternal tanshin funin was asked in a separate question across waves two to five, however the question was not included in the first survey. Participants who answered 'no' to the question about father residency and did not answer the question about tanshin funin were categorized as having paternal separation. Participants who answered 'yes' to the question about living with their father and did not answer the question about tanshin funin were excluded because we could not determine whether they lived with their father or if their father was on tanshin funin $(n=3)$. Participants who did not answer the question about living with their father and the question about tanshin funin were excluded ( $n=4481)$. There were no participants who did not answer the question about father residency but answered the question about tanshin funin. Our main exposure, cumulative occasions of paternal separation, was defined as the sum of occasions when paternal separation was reported, and was categorized as: always living with father, 1-2 occasions of paternal separation, 3-4 occasions of paternal separation, and 5 occasions of paternal separation $(n=15$ 214). Duration of paternal separation may differ by a year at most because the annual questionnaires only 
Participants who were boys ( $\mathrm{n}=24425)$

Participants who were girls ( $\mathrm{n}=22$ 590)

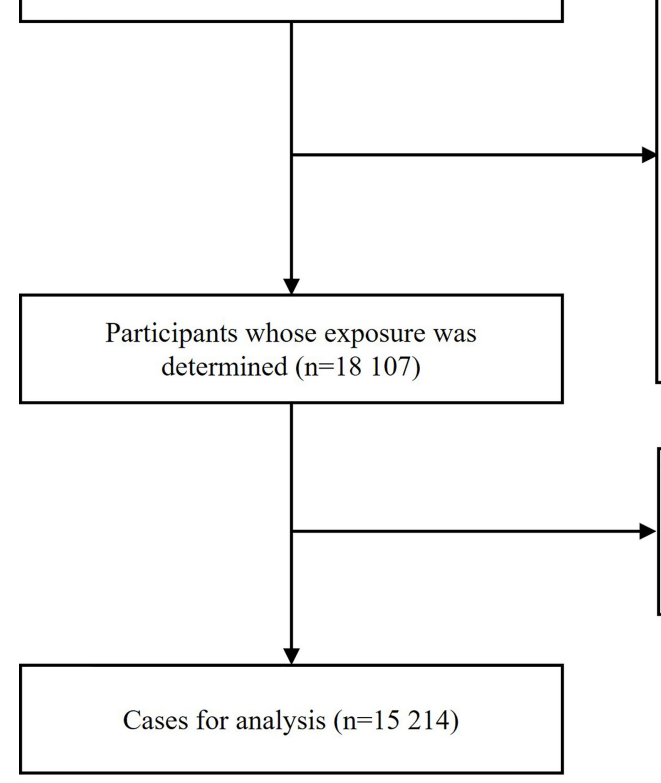

Participants with missing exposure variables among $1^{\text {st }}-5^{\text {th }}$ survey ( $\left.\mathrm{n}=\mathrm{a} 4483\right)$

- Participants whose paternal cohabitation and tanshin funin status are missing $(\mathrm{n}=4$ 481)

- Participants who answered as paternal cohabitation but had missing in paternal tanshin funin status $(\mathrm{n}=3)$

aSome participants belonged to both of the above two groups (i.e., the group of 4481 and the group of 3 ).

Participants whose height $\mathrm{z}$-score $-5 \mathrm{SD}>$ or

$3 \mathrm{SD}<$ among $6^{\text {th }}-15^{\text {th }}$ survey $(\mathrm{n}=2893)$

FIGURE 1 | Enrollment of study participants.

asked for the exact time point that the questionnaire was conducted, not the date that the father residency occurred.

Covariates were selected according to previous studies conducted among paternal absence and pubertal timing (4). Covariates included household income at age 0.5 , maternal age at first birth, maternal education level and grandparent cohabitation at age 0.5. Regarding maternal age at first birth, lower maternal age at first birth is associated with socioeconomic disadvantages (18) and maternal negative emotions including depression (19). Then, socioeconomic disadvantages (20) and maternal depression are associated with earlier pubertal timing of the child (21). Some researchers also argued that maternal depression leads to attachment difficulties (22) which could accelerate maturation (23). Thus, lower maternal age at first birth could be associated with child's earlier maturation. Since lower maternal age at first birth has also been linked to single parenthood $(4,18)$, we regarded maternal age at first birth as a confounder. Household income was included since previous research had pointed out the association with paternal absence (4) and early pubertal growth (5). Grandparent cohabitation was considered because it may lead to paternal absence, and it is also associated with childhood overweight that is associated with earlier maturation $(24,25)$.

Other covariates were parental smoking status at age 0.5, whether the mother had someone to consult about worries regarding child raising when the child was age 0.5 (i.e., maternal social capital), birth order, rapid weight gain during early childhood, number of siblings at age 4.5, and whether the child was overweight at age 4.5 defined as BMI z score of 1 SD or more according to WHO criteria (26). Information on parental smoking status and maternal social capital was from the first survey. These variables were included regarding previous research $(27,28)$. Rapid weight gain during the first two years of life is linked to earlier pubertal timing (28). Children from father-absent households are more likely to be bottle-fed during infancy, which is associated with rapid weight gain in the first year of life (29).

For maternal age at first birth, we subtracted mother's birthday from first child's birthday collected from birth record and first wave. Equivalized household income at age 0.5 was calculated based on responses from first wave. Maternal education level was collected in second wave and categorized 
as junior high school, high school, vocational school, and higher education. Grandparent cohabitation at age 0.5 was considered when one or more grandparents lived together. Overweight at age 4.5 was determined as BMI z score of $1 \mathrm{SD}$ or more according to WHO criteria (26). Rapid weight gain was determined as gaining more than $0.67 \mathrm{SD}$ of weight from birth to age 1.5 years old (28).

Outcome of interest was measured as age at peak height velocity (PHV). Although some prior studies used age at menarche as a measurement for pubertal timing $(4,5,7)$, age at PHV has also been used to determine pubertal timing (30-32) and has been known to coincide with decisive pubertal index such as menarche (32-34). We were not able to obtain data for menarche because such question was not included in the survey. Height and date of height measurement were reported by parents, which was shown to be accurate in comparison with objective measurement (35). We first calculated the slope for height growth in each of the two consecutive time points (height at $\mathrm{x}+1$ st survey - height at $\mathrm{xth}$ survey)/(age at $\mathrm{x}+1$ st survey - age at $x$ th survey) and selected the largest slope. Age at PHV was defined as the mean age between the two consecutive time points which the largest height slope was observed [(age at $\mathrm{x}+1$ st survey + age at $x$ th survey)/2]. Age at PHV was deemed as missing if it could not be calculated (e.g., when the data on height was missing in either of the two consecutive surveys) $(n=1355)$.

\section{Statistical Analysis}

We used multiple imputation using chained equations to impute missing values in age at PHV, household income at age 0.5, maternal age at first birth, maternal education level, parental smoking status at age 0.5 , maternal social capital when the child was age 0.5 , rapid weight gain during early childhood, and whether the child was overweight at age 4.5 and created 20 imputed datasets. Variables used in imputation included cumulative occasions of father separation, birth order and grandparent cohabitation at age 0.5 . The results of analyses using all the imputed datasets were combined using Rubin's rules for multiple imputation $(36,37)$. Multiple imputation imputed missing valuables for 0.01 to $11.7 \%$ of the participants for analysis $(n=15214)$.

We used linear regression model to estimate the effect of paternal separation on the age at PHV. In our sensitivity analysis, we also examined two alternative ways of assessing paternal separation: instability of paternal separation and commencement of continuous paternal separation. Instability of paternal separation was determined by the number of occasions when the respondents switched between 'paternal presence' and 'paternal separation' across the five waves $(n=15214)$. Since the sample was drawn from a population consisting of all babies born in January and July, a sensitivity analysis was also conducted by adjusting for the birth month.

In terms of defining onset of continuous paternal separation, we excluded all children whose fathers later returned and investigated the child's age when it occurred ( $n=14$ 550).

All analyses were performed with STATA SE statistical package, version 14 (StataCorp LP, College Station, ZTX, USA).

\section{RESULTS}

Table 1 summarizes the characteristics of the sample. Household income at the age of 0.5 years was lower as cumulative occasions of paternal separation increased. Maternal education level was lower in father-always-separated households compared to the others. Also, girls from father-always-separated households were more likely to be an only child, lived with their grandparents during infancy and overweight during early childhood. We also compared our analytic sample with full sample $(n=22$ 590) (Table Appendix 1). Characteristics of girls in analytic sample and full sample were similar.

Table 2 shows the association between cumulative occasions of paternal separation from ages 0.5 to 4.5 years and age at PHV using linear regression. After adjusting for potential confounders, girls whose fathers were always separated experienced $\mathrm{PHV} 0.47$ years (95\% CI: $-0.80,-0.15, \mathrm{p}=0.004$ ) earlier compared to girls whose father was always present (Model 1, Table 2). However, the intermediate categories of paternal separation (father separated on 1-2 occasions, 3-4 occasions) were not statistically significantly associated with age at PHV.

As a crude check of mediation, after including potential variables, girls who did not live with their father on all five occasions still experienced an earlier onset of PHV of 0.42 years (95\% CI: $-0.75,-0.10, \mathrm{p}=0.011$ ) (Model 2, Table 2). We also conducted sensitive analysis by adjusting for birth month as the population derived from those born in January and July. Girls from father-always-separated households still experienced 0.43 years earlier (95\% CI: $-0.75,-0.10, \mathrm{p}=0.010)$ maturation after adjustment.

Next, we turned to an alternative definition of exposure, that is, instability of paternal separation. The results (Model 1, Table Appendix 2) showed that while such instability was correlated with earlier peak velocity, the estimate was not statistically significant. Finally, when we looked at the onset of continuous paternal separation, our results showed that age at PHV comes earlier by 0.42 years when paternal separation was reported at the very first survey ( $95 \% \mathrm{CI}:-0.74,-0.09, \mathrm{p}=0.011)$. When paternal absence occurred after the age of 0.5 , the results were not significant.

\section{DISCUSSION}

This study found that cumulative paternal separation from infancy was associated with a significantly earlier age at PHV in girls. We also found that the cumulative effect from infancy was stronger than that of instability or onset of continual paternal separation at later ages. Previous studies have emphasized that the association between paternal absence and earlier pubertal timing is stronger when it occurs during early childhood (ages 0 through 5 years) than that occurring at later ages (4). We add to the literature the cumulative effect of physical paternal absence including tanshin funin on earlier age at PHV among girls.

Several explanations between father absence and earlier maturation have been suggested in previous research. The first possible mechanism linking paternal absence to earlier pubertal growth among girls is low SES and higher risk of overweight. Previous studies have shown that paternal absence is strongly correlated with lower SES (38), because such households rely on 
TABLE 1 | Characteristics of study participants from the Longitudinal Survey of Newborns in the 21st Century in unimputed original data (n=15214).

\begin{tabular}{|c|c|c|c|c|c|}
\hline \multirow[t]{2}{*}{ Variable } & & \multirow{2}{*}{$\begin{array}{l}\text { Always father present } \\
\mathrm{N}(\%) \text { or mean (SD) }\end{array}$} & \multirow{2}{*}{$\begin{array}{c}\begin{array}{c}\text { 1-2 times father } \\
\text { separation }\end{array} \\
\mathrm{N}(\%) \text { or mean (SD) }\end{array}$} & \multirow{2}{*}{$\begin{array}{c}\text { 3-4 times father } \\
\text { separation }\end{array}$} & \multirow{2}{*}{$\begin{array}{c}\begin{array}{c}\text { Always father } \\
\text { separation }\end{array} \\
\mathrm{N}(\%) \text { or mean (SD) }\end{array}$} \\
\hline & & & & & \\
\hline \multirow[t]{2}{*}{ Percentage of participants } & & 13494 & 1128 & 420 & 172 \\
\hline & & $(88.7)$ & $(7.4)$ & $(2.8)$ & $(1.1)$ \\
\hline \multirow[t]{4}{*}{ Age at peak height velocity } & Mean, years & 9.65 & 9.67 & 9.51 & 9.05 \\
\hline & & $(2.0)$ & $(2.1)$ & $(2.0)$ & $(2.0)$ \\
\hline & Missing & 1138 & 138 & 49 & 30 \\
\hline & & $(8.4)$ & $(12.2)$ & $(11.7)$ & $(17.4)$ \\
\hline \multirow[t]{4}{*}{ Household income at age 0.5} & Mean, million JPY & 2.89 & 2.66 & 2.51 & 1.27 \\
\hline & & (1.9) & $(1.5)$ & $(1.6)$ & $(1.5)$ \\
\hline & Missing & 229 & 14 & 8 & 0 \\
\hline & & $(1.7)$ & $(1.2)$ & $(1.9)$ & $(0.0)$ \\
\hline \multirow[t]{12}{*}{ Maternal age at first birth, years } & $<25$ & 2655 & 320 & 137 & 53 \\
\hline & & $(19.7)$ & $(28.4)$ & $(32.6)$ & $(30.8)$ \\
\hline & $25-29$ & 6805 & 518 & 186 & 50 \\
\hline & & $(50.4)$ & $(45.9)$ & $(44.3)$ & $(29.1)$ \\
\hline & $30-34$ & 3284 & 249 & 84 & 43 \\
\hline & & (24.3) & $(22.1)$ & (20.0) & (25.0) \\
\hline & $35-39$ & 688 & 37 & 11 & 19 \\
\hline & & $(5.1)$ & (3.3) & $(2.6)$ & (11.1) \\
\hline & $\geqq 40$ & 61 & 4 & 2 & 7 \\
\hline & & $(0.5)$ & $(0.4)$ & $(0.5)$ & $(4.1)$ \\
\hline & Missing & 1 & 0 & 0 & 0 \\
\hline & & $(0.01)$ & $(0.0)$ & $(0.0)$ & $(0.0)$ \\
\hline \multirow[t]{12}{*}{ Maternal education } & Junior high school & 404 & 45 & 26 & 27 \\
\hline & & (3.0) & $(4.0)$ & $(6.2)$ & $(15.7)$ \\
\hline & High school & 5100 & 432 & 178 & 78 \\
\hline & & $(37.8)$ & (38.3) & $(42.4)$ & $(45.4)$ \\
\hline & Vocational school & 5817 & 478 & 165 & 56 \\
\hline & & $(43.1)$ & $(42.4)$ & (39.3) & (32.6) \\
\hline & Higher education & 2094 & 170 & 47 & 10 \\
\hline & & (15.5) & $(15.1)$ & $(11.2)$ & $(5.8)$ \\
\hline & Others & 16 & 1 & 0 & 0 \\
\hline & & $(0.1)$ & $(0.1)$ & $(0.0)$ & $(0.0)$ \\
\hline & Missing & 63 & 2 & 4 & 1 \\
\hline & & $(0.5)$ & $(0.2)$ & $(1.0)$ & $(0.6)$ \\
\hline \multirow[t]{4}{*}{ Grandparent cohabitation at age 0.5} & Yes & 2770 & 256 & 110 & 108 \\
\hline & & $(20.5)$ & $(22.7)$ & $(26.2)$ & $(62.8)$ \\
\hline & No & 10724 & 872 & 310 & 64 \\
\hline & & $(79.5)$ & (77.3) & $(73.8)$ & $(37.2)$ \\
\hline \multirow[t]{6}{*}{ Maternal smoking status at age 0.5} & Yes & 1766 & 194 & 110 & 53 \\
\hline & & $(13.1)$ & $(17.2)$ & $(26.2)$ & $(30.8)$ \\
\hline & No & 11677 & 929 & 307 & 117 \\
\hline & & $(86.5)$ & $(82.4)$ & $(73.1)$ & $(68.0)$ \\
\hline & Missing & 51 & 5 & 3 & 2 \\
\hline & & $(0.38)$ & $(0.4)$ & $(0.7)$ & $(1.2)$ \\
\hline \multirow[t]{6}{*}{ Paternal smoking status at age 0.5} & Yes & 8022 & 712 & 298 & 18 \\
\hline & & $(59.5)$ & $(63.1)$ & $(71.0)$ & $(10.5)$ \\
\hline & No & 5400 & 386 & 99 & 12 \\
\hline & & $(40.0)$ & $(34.2)$ & $(23.6)$ & $(7.0)$ \\
\hline & Missing & 72 & 30 & 23 & 142 \\
\hline & & $(0.5)$ & $(2.7)$ & $(5.5)$ & (82.6) \\
\hline \multirow[t]{6}{*}{ Maternal social capital at age 0.5} & Yes & 13072 & 1073 & 406 & 156 \\
\hline & & (96.9) & $(95.1)$ & $(96.7)$ & $(90.7)$ \\
\hline & No & 89 & 8 & 3 & 10 \\
\hline & & $(0.7)$ & $(0.7)$ & $(0.7)$ & $(5.8)$ \\
\hline & Missing & 333 & 47 & 11 & 6 \\
\hline & & $(2.5)$ & $(4.2)$ & $(2.6)$ & (3.5) \\
\hline Birth order & First & 6710 & 547 & 211 & 115 \\
\hline & & $(49.7)$ & $(48.5)$ & $(50.2)$ & (66.9) \\
\hline & Second & 4966 & 428 & 142 & 38 \\
\hline & & (36.8) & (38.0) & (33.8) & (22.1) \\
\hline & Third & 1535 & 135 & 57 & 14 \\
\hline & & $(11.4)$ & (12.0) & (13.6) & $(8.1)$ \\
\hline & Fourth or later & 283 & 18 & 10 & 5 \\
\hline
\end{tabular}


TABLE 1 | Continued

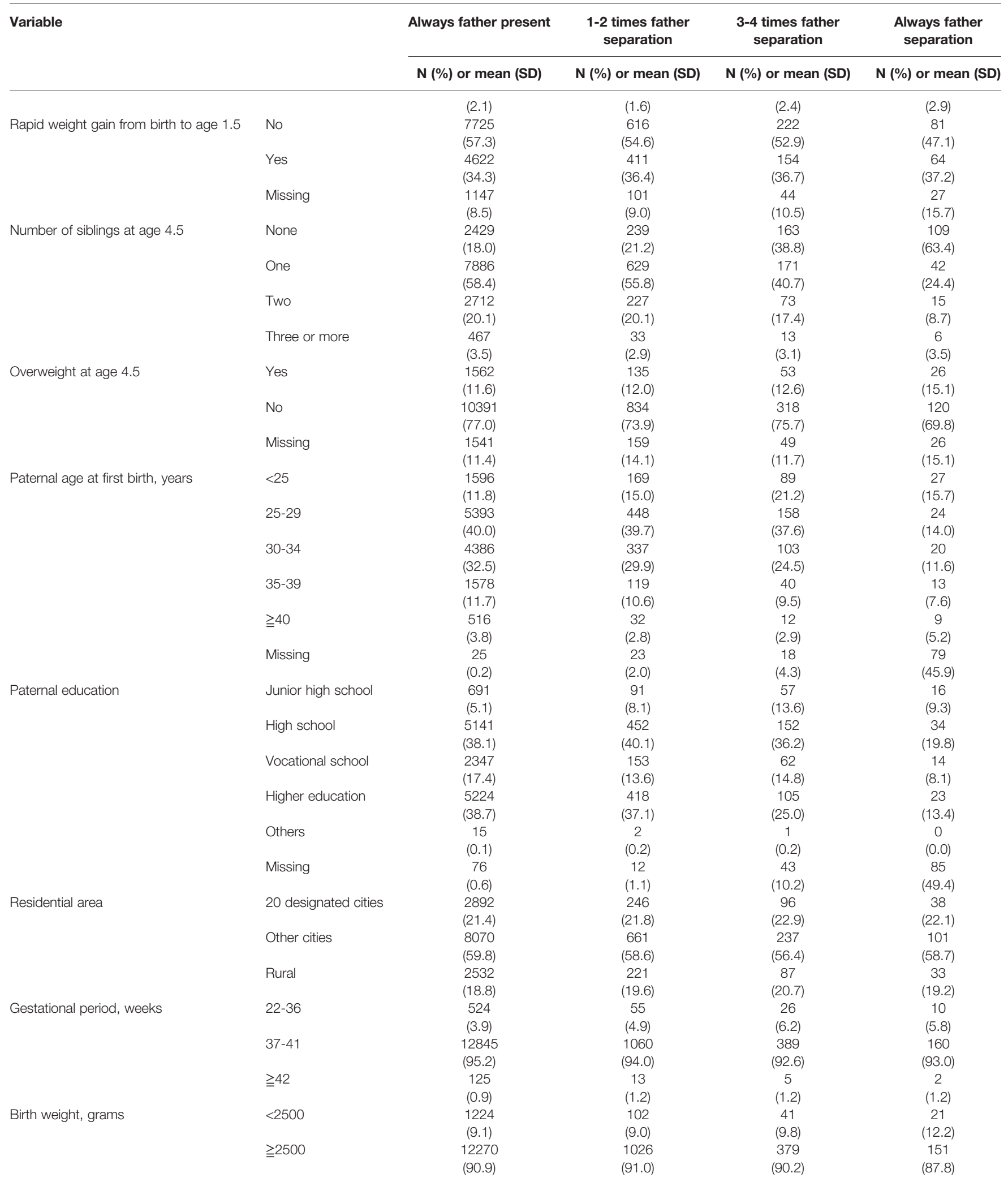


TABLE 2 | Associations between cumulative occasions of father separation at ages 0.5-4.5 and age at peak height velocity (years) using linear regression (n=15214).

\begin{tabular}{|c|c|c|c|c|}
\hline & & Crude & Model 1 & Model 2 \\
\hline & & $\begin{array}{c}\beta \\
(95 \% \mathrm{Cl})\end{array}$ & $\begin{array}{c}\beta \\
(95 \% \mathrm{Cl})\end{array}$ & $\begin{array}{c}\beta \\
(95 \% \mathrm{Cl})\end{array}$ \\
\hline Always father present & & Ref & Ref & Ref \\
\hline 1-2 times father separation & & $\begin{array}{c}0.002 \\
(-0.13,0.13)\end{array}$ & $\begin{array}{c}0.01 \\
(-0.12,0.15)\end{array}$ & $\begin{array}{c}0.03 \\
(-0.10,0.16)\end{array}$ \\
\hline 3-4 times father separation & & $\begin{array}{c}-0.14 \\
(-0.35,0.08)\end{array}$ & $\begin{array}{c}-0.11 \\
(-0.32,0.11)\end{array}$ & $\begin{array}{c}-0.06 \\
(-0.28,0.15)\end{array}$ \\
\hline Always father separation & & $\begin{array}{c}-0.58 \\
(-0.90,-0.26)\end{array}$ & $\begin{array}{c}-0.47 \\
(-0.80,-0.15)\end{array}$ & $\begin{array}{c}-0.42 \\
(-0.75,-0.10)\end{array}$ \\
\hline Household income & & - & $\begin{array}{c}1.98 \times 10^{-7} \\
\left(-1.73 \times 10^{-6}, 2.12 \times 10^{-6}\right)\end{array}$ & $\begin{array}{c}-6.70 \times 10^{-8} \\
\left(-1.99 \times 10^{-6}, 1.86 \times 10^{-6}\right)\end{array}$ \\
\hline Maternal age at first birth & & - & $\begin{array}{c}0.01 \\
(-0.001,0.02)\end{array}$ & $\begin{array}{c}0.01 \\
(-0.001,0.02)\end{array}$ \\
\hline Maternal education level & $\begin{array}{l}\text { Junior high school } \\
\text { High school }\end{array}$ & - & $\begin{array}{c}\text { Ref } \\
0.16 \\
(-0.05,0.37)\end{array}$ & $\begin{array}{c}\text { Ref } \\
0.12 \\
(-0.09,0.34)\end{array}$ \\
\hline & Vocational school & - & $\begin{array}{c}0.23 \\
(0.02,0.43)\end{array}$ & $\begin{array}{c}0.17 \\
(-0.05,0.38)\end{array}$ \\
\hline & Higher education & - & $\begin{array}{c}0.25 \\
(0.03,0.47)\end{array}$ & $\begin{array}{c}0.18 \\
(-0.04,0.41)\end{array}$ \\
\hline & Others & - & $\begin{array}{c}0.02 \\
(-0.98,1.02)\end{array}$ & $\begin{array}{c}-0.03 \\
(-1.04,0.97)\end{array}$ \\
\hline Grandparent cohabitation at age 0.5 & $\begin{array}{l}\text { No } \\
\text { Yes }\end{array}$ & - & $\begin{array}{c}\text { Ref } \\
-0.16 \\
(-0.24,-0.07)\end{array}$ & $\begin{array}{c}\text { Ref } \\
-0.15 \\
(-0.24,-0.06)\end{array}$ \\
\hline Maternal smoking status at age 0.5 & $\begin{array}{l}\text { No } \\
\text { Yes }\end{array}$ & - & - & $\begin{array}{c}\text { Ref } \\
-0.09 \\
(-0.19,0.02)\end{array}$ \\
\hline Paternal smoking status at age 0.5 & $\begin{array}{l}\text { No } \\
\text { Yes }\end{array}$ & - & - & $\begin{array}{c}\text { Ref } \\
-0.08 \\
(-0.15,0.004)\end{array}$ \\
\hline Maternal social capital at age 0.5 & $\begin{array}{l}\text { Yes } \\
\text { No }\end{array}$ & - & - & $\begin{array}{c}\text { Ref } \\
0.02 \\
(-0.39,0.43)\end{array}$ \\
\hline Birth order & & - & - & $\begin{array}{c}-0.06 \\
(-0.12,0.001)\end{array}$ \\
\hline Rapid weight gain from birth to age 1.5 & $\begin{array}{l}\text { No } \\
\text { Yes }\end{array}$ & - & - & $\begin{array}{c}\text { Ref } \\
-0.10 \\
(-0.18,-0.03)\end{array}$ \\
\hline Number of siblings at age 4.5 & & - & - & $\begin{array}{c}0.07 \\
(0.004,0.13)\end{array}$ \\
\hline Overweight at age 4.5 & $\begin{array}{l}\text { No } \\
\text { Yes }\end{array}$ & - & $\begin{array}{l}- \\
-\end{array}$ & $\begin{array}{c}\text { Ref } \\
-0.28 \\
(-0.39,-0.17)\end{array}$ \\
\hline
\end{tabular}

Bolded values indicate statistical significance at $p<0.05$.

Model 1 adjusted for household income, maternal age at first birth, maternal education level and grandparent cohabitation.

Model 2 adjusted for parental smoking status, maternal social capital, birth order, rapid weight gain, number of siblings and childhood overweight in addition to covariates included in Model1.

the income of a single parent (usually the mother), and women usually earn less compared to men due to the gender wage gap (39). In addition, socioeconomic disadvantage is correlated with a higher risk of obesity in high-income countries where energydense food is cheaper and more readily accessible to lowincomed families (40). Furthermore, overweight is associated with earlier pubertal timing due to accelerated gonadal function stemming from increased insulin resistance, androgens, and leptin levels $(8,24)$. This trend has also been observed in Japan (41) and was also seen in the population we analyzed. As seen in Table 1, father-always-absent families had lower household income at the age of 0.5 , and girls from such families were more likely to be overweight during early childhood. However, low SES is unlikely to fully explain our findings because earlier maturation was still observed after adjusting for household income and overweight (Table 2, Model 2). This can be because girls who experience father absence due to tanshin funin did not experience economic disadvantage in same ways as their peers whose father was absent for different reasons (i.e. divorce/death). However, we were not able to differentiate father absence according to the reason because the first survey lacked questions on tanshin funin. 
An alternative explanation invokes the role of chronic stress and increased sex hormone secretion induced from paternal absence $(4,42)$. When stress is of a chronic nature, the HPA (hypothalamicpituitary-adrenal) axis and the HPG (hypothalamic-pituitarygonadal) axis can become dysregulated, triggering increased secretion of GnRH (gonadotropin-releasing hormone) and downstream gonadotropin hormones (43) that cause early maturation and pubertal timing. In line with this, studies have shown that chronic stress (including paternal absence and parent conflict) is associated with earlier puberty (4). However, in our study, we could not confirm the effect of stress as we did not have such information in the survey. Although other proxy measures of stress such as instability of paternal separation did not show a significant association with earlier pubertal timing, future studies assessing whether stress mediates the association are warranted.

Besides the aforementioned pathways, some researchers have argued for an evolutionary basis for the correlation between social-environmental adversity and early pubertal timing $(12,14$, 44). Social adversity (including poverty, parental instability, high stress) during early childhood tends to foster more insecure attachment between parents and children. In turn, insecure attachment may give rise to behavioral problems (externalizing symptoms) and depression/anxiety (internalizing symptoms). Girls are more likely to develop internalizing problems, which correlates with lower metabolism, storage of fat, and menarche stimulation - part of the biological and behavioral "quantityoriented reproductive strategy" (14). Such a strategy might maximize the chance of survival at the level of the individual within a species in the context of adversity. Future studies should assess whether biological mechanisms (e.g., hormonal changes) that are consistent with the evolutionary theory may explain association between paternal absence and earlier pubertal timing.

Although prior studies in Japanese girls showed similar results as our study on mean age at PHV (45), some had different results (31). This gap may be because our study used data from recent surveys, while prior studies used older data. Studies pointed out that there is a trend of maturation acceleration over the past decades (46). The difference in height cutoff may also explain the difference in age at PHV.

This study has several limitations. First, the survey only included height as a measure of pubertal development and lacked information on age at menarche $(4,5)$ or breast or pubic hair development (27). Furthermore, height measurement was limited annually. Nonetheless, height is easy to measure, and age at PHV is suggested to coincide with other pubertal index, thus can be applicable to detect signs of early puberty $(47,48)$ that enables future possible interventions for early maturation. Since it is also difficult to detect puberty-related growth acceleration that occurs prior to its peak, future study should combine other measurements for puberty to confirm our findings, as well as measure height at several points within a year. Second, we could not obtain measurements of stress or hormone levels that might help explain the association between father absence and earlier maturation in terms of chronic stress/increased hormone pathway or the evolutionary theory. Third, we were not able to include pubertal timing of the parents because the survey lacked maternal age of menarche as well as age of paternal puberty. Fourth, we did not have sufficient observation time for the boys in the sample to attain PHV (49). Fifth, we were not able to separately analyze paternal separation resulting from divorce/death and tanshin funin. This is because there was no question on tanshin funin in the first survey and we could not clarify whether paternal separation was due to tanshin funin or divorce/death. Sixth, paternal absence was selfreported. Since the questionnaire only queried father cohabitation at the exact timepoint of survey, the length of paternal separation may differ by a year at most. Seventh, we did not have information on whether the father on tanshin funin had contact with the family. Eighth, children's height information was self-reported from a family member. Although it is possible that there may be inaccurate records, especially in outliers, we consider that our sample was representative of the Japanese population based on a previous cohort profile study (16). Furthermore, characteristics of girls in our analytic sample and full sample were similar under comparison. Lastly, we did not ascertain whether the living father was the biological father (5).

The implication of this study is that girls who experienced cumulative paternal separation from early infancy are at increased risk of earlier puberty and health problems accompanying it. This study adds to the literature that in terms of earlier onset of puberty, not only paternal absence due to divorce/death plays a part but also physical and functional father absence due to tanshin funin. Although SES has been considered as an important pathway between paternal absence and earlier maturation, it does not fully explain the association in our study. Future studies should clarify the mechanisms including stress that might explain our findings. Girls who experienced early maturation may be differentiated from peers due to their appearance, and thus have an increased risk of psychological stress (4) in addition to existing stress caused by the family structure. Given the increased risk of experiencing earlier puberty in girls who experienced paternal separation, programs that aim to provide support for pubertal psychological care should also provide comprehensive care to girls and their families who experienced tanshin funin as well.

\section{CONCLUSION}

We found that paternal separation throughout ages 0.5 to 4.5 years leads to earlier age at PHV among girls. This effect was cumulative and was stronger than that of instability or onset of paternal separation at later ages.

\section{DATA AVAILABILITY STATEMENT}

The original contributions presented in the study are included in the article/Supplementary Material. Further inquiries can be directed to the corresponding author.

\section{ETHICS STATEMENT}

The studies involving human participants were reviewed and approved by the Ethics Committee of Tokyo Medical and Dental 
University. Written informed consent for participation was not required for this study in accordance with the national legislation and the institutional requirements.

\section{AUTHOR CONTRIBUTIONS}

Conceptualization, AK, NN, and TF. Methodology, AK and NN. Software, AK. Validation, NN. Formal analysis, AK. Investigation, AK. Resources, TF. Data curation, AK and NN. Writing - original draft preparation, AK. Writing - review and editing, NN. Visualization, AK. Supervision, TF. Project Administration, TF. All authors contributed to the article and approved the submitted version.

\section{FUNDING}

This study was supported by Grant-in-Aid for Challenging Research (Pioneering) from the Japan Society for the Promotion

\section{REFERENCES}

1. Ahlgren M, Melbye M, Wohlfahrt J, Sørensen TI. Growth Patterns and the Risk of Breast Cancer in Women. N Engl J Med (2004) 351(16):1619-26. doi: 10.1056/NEJMoa040576

2. Walvoord EC. The Timing of Puberty: Is it Changing? Does It Matter? J Adolesc Health (2010) 47(5):433-9. doi: 10.1016/j.jadohealth.2010.05.018

3. Moorman PG, Palmieri RT, Akushevich L, Berchuck A, Schildkraut JM. Ovarian Cancer Risk Factors in African-American and White Women. Am J Epidemiol (2009) 170(5):598-606. doi: 10.1093/aje/kwp176

4. Culpin I, Heron J, Araya R, Melotti R, Lewis G, Joinson C. Father Absence and Timing of Menarche in Adolescent Girls From a UK Cohort: The Mediating Role of Maternal Depression and Major Financial Problems. J Adolesc (2014) 37(3):291-301. doi: 10.1016/j.adolescence.2014.02.003

5. Karapanou O, Papadimitriou A. Determinants of Menarche. Reprod Biol Endocrinol (2010) 8:115. doi: 10.1186/1477-7827-8-115

6. Mendle J, Leve LD, Van Ryzin M, Natsuaki MN, Ge X. Associations Between Early Life Stress, Child Maltreatment, and Pubertal Development Among Girls in Foster Care. J Res Adolesc (2011) 21(4):871-80. doi: 10.1111/j.15327795.2011.00746.x

7. Persson I, Ahlsson F, Ewald U, Tuvemo T, Qingyuan M, von Rosen D, et al. Influence of Perinatal Factors on the Onset of Puberty in Boys and Girls: Implications for Interpretation of Link With Risk of Long Term Diseases. Am J Epidemiol (1999) 150(7):747-55. doi: 10.1093/oxfordjournals.aje.a010077

8. Aghaee S, Laurent CA, Deardorff J, Ferrara A, Greenspan LC, Quesenberry $\mathrm{CP}$, et al. Associations of Maternal Gestational Weight Gain and Obesity With the Timing of Pubertal Onset in Daughters. Am J Epidemiol (2019) 188 (7):1262-9. doi: 10.1093/aje/kwz068

9. Ministry of Health Labor and Welfare. Vital Statistics of Japan 2018. Ministry of Health Labor and Welfare . Available at: https://www.mhlw.go.jp/english/ database/db-hw/dl/81-1a2en.pdf (Accessed February 18th, 2020).

10. Japan Institute for Labor Policy and Training. Result Summary of "Survey on the Actual Conditions of Corporate Transfers". Japan Institute for Labor Policy and Training. 2nd March, 2021 . Available at: https://www.mhlw.go.jp/file/05Shingikai-11901000-Koyoukintoujidoukateikyoku-Soumuka/0000149700.pdf (Accessed 2nd March, 2021).

11. Tanaka Y. The Effect of Relocation-Induced Separation on Their Families. Jpn J Educ Psychol (1988) p:229-37. doi: 10.5926/jjep1953.36.3_229

12. Draper P, Harpending H. Father Absence and Reproductive Strategy: An Evolutionary Perspective. J Anthropol Res (1982) p:255-73. doi: 10.1086/ jar.38.3.3629848

13. Deardorff J, Ekwaru JP, Kushi LH, Ellis BJ, Greenspan LC, Mirabedi A, et al. Father Absence, Body Mass Index, and Pubertal Timing in Girls: Differential Effects by Family Income and Ethnicity. J Adolesc Health (2011) 48(5):441-7. doi: 10.1016/j.jadohealth.2010.07.032 of Science (Grant Number 21K18294). AK is a recipient of a scholarship by the Japan Student Services Organization.

The funder had no role in study design, data collection and analysis, decision to publish, or preparation of the manuscript.

\section{ACKNOWLEDGMENTS}

The authors wish to thank Professor Ichiro Kawachi and Dr. Shiho Kino for critically reviewing the manuscript.

\section{SUPPLEMENTARY MATERIAL}

The Supplementary Material for this article can be found online at: https://www.frontiersin.org/articles/10.3389/fendo.2021.766728/ full\#supplementary-material

14. Belsky J, Steinberg L, Draper P. Childhood Experience, Interpersonal Development, and Reproductive Strategy: And Evolutionary Theory of Socialization. Child Dev (1991) 62(4):647-70. doi: 10.2307/1131166

15. Sear R, Sheppard P, Coall DA. Cross-Cultural Evidence Does Not Support Universal Acceleration of Puberty in Father-Absent Households. Philos Trans $R$ Soc Lond B Biol Sci (2019) 374(1770):20180124. doi: 10.1098/rstb.2018.0124

16. Fuse K, Nishi N, Ikeda N. Cohort Profile: 2001 Cohort of the Longitudinal Survey of Newborns in the 21st Century. Int J Epidemiol (2017) 46(5):13981398f. doi: 10.1093/ije/dyx104

17. WHO Expert Committee on Physical Status: The Use and Interpretation of Anthropometry (1993 : Geneva, Switzerland) \& World Health Organization. Physical Status: The Use and Interpretation of Anthropometry. Report of a WHO Expert Committee. World Health Organ Tech Rep Ser (1995) 854:1452. Geneva: World Health Organization.

18. Deardorff J, Gonzales NA, Christopher FS, Roosa MW, Millsap RE. Early Puberty and Adolescent Pregnancy: The Influence of Alcohol Use. Pediatrics (2005) 116(6):1451-6. doi: 10.1542/peds.2005-0542

19. Bang KS, Kim S, Lee G, Jeong Y, Shin DA, Kim M. Intervention Studies on the Enhancement of Self-Concept Among Adolescent Mothers: A Systematic Review. J Psychosoc Nurs Ment Health Serv (2021) 1:1-9. doi: 10.3928/ 02793695-20210819-03

20. Ellis BJ, Essex MJ. Family Environments, Adrenarche, and Sexual Maturation: A Longitudinal Test of a Life History Model. Child Dev (2007) 78(6):1799817. doi: 10.1111/j.1467-8624.2007.01092.x

21. Ellis BJ, Garber J. Psychosocial Antecedents of Variation in Girls' Pubertal Timing: Maternal Depression, Stepfather Presence, and Marital and Family Stress. Child Dev (2000) 71(2):485-501. doi: 10.1111/1467-8624.00159

22. Siegel RS, Brandon AR. Adolescents, Pregnancy, and Mental Health. J Pediatr Adolesc Gynecol (2014) 27(3):138-50. doi: 10.1016/j.jpag.2013.09.008

23. Belsky J, Houts RM, Fearon RM. Infant Attachment Security and the Timing of Puberty: Testing an Evolutionary Hypothesis. Psychol Sci (2010) 21 (9):1195-201. doi: 10.1177/0956797610379867

24. Ahmed ML, Ong KK, Dunger DB. Childhood Obesity and the Timing of Puberty. Trends Endocrinol Metab (2009) 20(5):237-42. doi: 10.1016/ j.tem.2009.02.004

25. Morita A, Ochi M, Isumi A, Fujiwara T. Association Between Grandparent Coresidence and Weight Change Among First-Grade Japanese Children Pediatr Obes (2019) 14(8):e12524. doi: 10.1111/ijpo.12524

26. de Onis M, Onyango AW, Borghi E, Siyam A, Nishida C, Siekmann J. Development of a WHO Growth Reference for School-Aged Children and Adolescents. Bull World Health Organ (2007) 85(9):660-7. doi: 10.2471/ blt.07.043497

27. Gold R, Kennedy B, Connell F, Kawachi I. Teen Births, Income Inequality, and Social Capital: Developing an Understanding of the Causal Pathway. Health Place (2002) 8(2):77-83. doi: 10.1016/s1353-8292(01)00027-2 
28. Karaolis-Danckert N, Buyken AE, Sonntag A, Kroke A. Birth and Early Life Influences on the Timing of Puberty Onset: Results From the DONALD (DOrtmund Nutritional and Anthropometric Longitudinally Designed) Study. Am J Clin Nutr (2009) 90(6):1559-65. doi: 10.3945/ajcn.2009.28259

29. Noll JG, Trickett PK, Long JD, Negriff S, Susman EJ, Shalev I, et al. Childhood Sexual Abuse and Early Timing of Puberty. J Adolesc Health (2017) 60(1):6571. doi: 10.1016/j.jadohealth.2016.09.008

30. Sanders JO, Qiu X, Lu X, Duren DL, Liu RW, Dang D, et al. The Uniform Pattern of Growth and Skeletal Maturation During the Human Adolescent Growth Spurt. Sci Rep (2017) 7(1):16705. doi: 10.1038/s41598-017-16996-w

31. Yoshii K, Tanaka T. Establishment of a Longitudinal Growth Chart Corresponding to Pubertal Timing. Clin Pediatr Endocrinol (2018) 27 (4):215-24. doi: 10.1297/cpe.27.215

32. Aksglaede L, Olsen LW, Sørensen TI, Juul A. Forty Years Trends in Timing of Pubertal Growth Spurt in 157,000 Danish School Children. PloS One (2008) 3 (7):e2728. doi: 10.1371/journal.pone. 0002728

33. Tanner JM, Whitehouse RH, Takaishi M. Standards From Birth to Maturity for Height, Weight, Height Velocity, and Weight Velocity: British Children, 1965. I Arch Dis Child (1966) 41(219):454-71. doi: 10.1136/adc.41.219.454

34. Watanabe N, Kobayashi N. Predicting the Onset of Menarche From Height Spurt: Using Individual Growth Curves. Jpn: School Health (2020) 62(5):27383. doi: $10.20812 /$ jpnjschhealth.62.5_273

35. Sekine M, Yamagami T, Hamanishi S, Kagamimori S. Accuracy of the Estimated Prevalence of Childhood Obesity From Height and Weight Values Reported by Parents: Results of the Toyama Birth Cohort Study. J Epidemiol (2002) 12(1):9-13. doi: 10.2188/jea.12.9

36. Rubin DB. The Calculation of Posterior Distributions by Data Augmentation: Comment: A Noniterative Sampling/Importance Resampling Alternative to the Data Augmentation Algorithm for Creating a Few Imputations When Fractions of Missing Information Are Modest: The SIR Algorithm. J Am Stat Assoc: Taylor Francis Ltd (1987) 82(398):543-6. doi: 10.2307/2289460

37. Sterne JA, White IR, Carlin JB, Spratt M, Royston P, Kenward MG, et al. Multiple Imputation for Missing Data in Epidemiological and Clinical Research: Potential and Pitfalls. BMJ (2009) 338:b2393. doi: 10.1136/ bmj.b2393

38. Lu YC, Walker R, Richard P, Younis M. Inequalities in Poverty and Income Between Single Mothers and Fathers. Int J Environ Res Public Health (2019) 17 (1):135. doi: 10.3390/ijerph17010135

39. Japan Institute for Labor Policy and Training A Quick Look at Long-Term Labor Statistics by Graph . Available at: https://www.jil.go.jp/kokunai/ statistics/timeseries/html/g0406.html (Accessed January 8th, 2020).

40. Ueda P, Kondo N, Fujiwara T. The Global Economic Crisis, Household Income and Pre-Adolescent Overweight and Underweight: A Nationwide Birth Cohort Study in Japan. Int J Obes (Lond) (2015) 39(9):1414-20. doi: 10.1038/ijo.2015.90
41. Hasegawa T. Poverty and Richness as Seen From Food Development, In: The Society of Developmental Psychology (Accessed November 1st, 2019).

42. Chisholm JS. The Evolutionary Ecology of Attachment Organization. Hum Nat (1996) 7(1):1-37. doi: 10.1007/BF02733488

43. Oyola MG, Handa RJ. Hypothalamic-Pituitary-Adrenal and HypothalamicPituitary-Gonadal Axes: Sex Differences in Regulation of Stress Responsivity. Stress (2017) 20(5):476-94. doi: 10.1080/10253890.2017.1369523

44. Moffitt TE, Caspi A, Belsky J, Silva PA. Childhood Experience and the Onset of Menarche: A Test of a Sociobiological Model. Child Dev (1992) 63(1):4758. doi: 10.2307/1130900

45. Yokoya M, Higuchi Y. Geographical Differences in the Population-Based Cross-Sectional Growth Curve and Age at Peak Height Velocity With Respect to the Prevalence Rate of Overweight in Japanese Children. Int J Pediatr (2014) 2014:867890. doi: 10.1155/2014/867890

46. Farello G, Altieri C, Cutini M, Pozzobon G, Verrotti A. Review of the Literature on Current Changes in the Timing of Pubertal Development and the Incomplete Forms of Early Puberty. Front Pediatr (2019) 7:147. doi: $10.3389 /$ fped.2019.00147

47. Suwa S, Tachibana K, Maesaka H, Tanaka T, Susumu Y. Longitudinal Standards for Height and Height Velocity for Japanese Children From Birth to Maturity. Clin Pediatr Endocrinol (1992) 1(1):5-13. doi: 10.1297/cpe.1.5

48. Stewart SD, Menning CL. Family Structure, Nonresident Father Involvement, and Adolescent Eating Patterns. J Adolesc Health (2009) 45(2):193-201. doi: 10.1016/j.jadohealth.2009.01.005

49. Ninomiya R, Higuchi Y, Chiba K. Studies on Body Form Classification on Boys and Girls. Jpn Hum Factors Ergon Soc (1988) 24(6):403-7. doi: 10.5100/ jje.24.403

Conflict of Interest: The authors declare that the research was conducted in the absence of any commercial or financial relationships that could be construed as a potential conflict of interest.

Publisher's Note: All claims expressed in this article are solely those of the authors and do not necessarily represent those of their affiliated organizations, or those of the publisher, the editors and the reviewers. Any product that may be evaluated in this article, or claim that may be made by its manufacturer, is not guaranteed or endorsed by the publisher.

Copyright (C) 2021 Katagiri, Nawa and Fujiwara. This is an open-access article distributed under the terms of the Creative Commons Attribution License (CC BY). The use, distribution or reproduction in other forums is permitted, provided the original author(s) and the copyright owner(s) are credited and that the original publication in this journal is cited, in accordance with accepted academic practice. No use, distribution or reproduction is permitted which does not comply with these terms. 